DOI: $10.20961 /$ jpscr.v4i1.28948

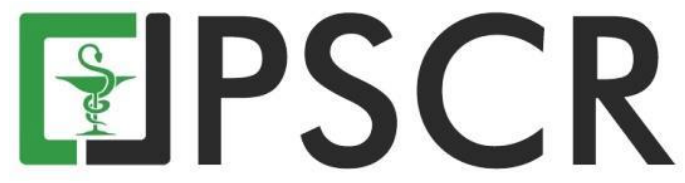

\title{
Analisis Kandungan Timbal dalam Beberapa Sediaan Kosmetik yang Beredar di Kota Surakarta
}

\author{
Adi Yugatama*, Adiba K. Mawarni, Hana Fadillah dan Siti N. Zulaikha \\ Program Studi Farmasi, Fakultas Matematika dan Ilmu Pengetahuan Alam, Universitas Sebelas Maret \\ *email korespondensi : adi.yugatama@staff.uns.ac.id
}

\begin{abstract}
Abstrak: Penggunaan sediaan kosmetik di Indonesia semakin meningkat. Beberapa sediaan kosmetika yang sering digunakan oleh masyarakat adalah eye-liner pencil, bedak, dan lipstik. Sediaan kosmetik dapat dikatakan aman apabila memenuhi jumlah maksimum kadar timbal yang sesuai dengan persyaratan yang ada. Penelitian ini bertujuan untuk mengetahui kadar logam timbal dalam beberapa sediaan kosmestik yang beredar di Kota Surakarta. Pengambilan sampel sediaan kosmetik dilakukan menggunakan teknik purposive sampling dengan kriteria 3 jenis sediaan kosmetik (eye-liner pencil, bedak, dan lipstik) yang beredar di Kota Surakarta, warna, dan harga. Preparasi sampel dilakukan dengan metode destruksi basah dengan campuran larutan asam $\mathrm{HNO}_{3}$ dan $\mathrm{HCl}$ (1:3). Sampel dianalisis menggunakan spektrofotometer serapan atom (SSA) dan diperoleh nilai absorbansinya dan dimasukkan ke dalam kurva kalibrasi sehingga dapat dihitung kadar timbal dalam sampel. Hasil analisis diperoleh bahwa kadar timbal terbesar terdapat pada sediaan lipstik yaitu sebesar 23,1683 $\pm 0,1225 \mathrm{mg} / \mathrm{kg}$ dan kadar timbal terendah terdapat pada sediaan bedak yaitu sebesar 0,6001 $\pm 0,0092 \mathrm{mg} / \mathrm{kg}$. Semua sediaan eye-liner pencil, bedak, dan lipstik yang beredar di Kota Surakarta telah memenuhi persyaratan batas maksimum kandungan timbal yang dipersyaratkan oleh BPOM, kecuali dua sampel lipstik yang tidak teregistrasi BPOM.
\end{abstract}

Kata kunci: Timbal; Eye-liner pencil; Bedak padat; Lipstik; Surakarta, Spektrofotometer serapan atom

\begin{abstract}
Analysis of Lead Contain in Various Cosmetics Marketed in Surakarta City. The use of cosmetic preparations in Indonesia is increasing. Some cosmetic preparations that are widely used are eye-liner pencil, compact or loose powder, and lipstick. Cosmetic preparations categorized as safe if they meet the maximum amount of lead content in accordance with existing requirements. This study was aimed to determine the levels of lead in some cosmetics preparation marketed in Surakarta City. Sampling of cosmetic preparations was carried out using a purposive sampling technique with the criteria of 3 types of cosmetic preparations (eye-liner pencil, powder, and lipstick) circulating in Surakarta City, color, and price. Sample preparation was carried out by wet destruction method with a mixture of $\mathrm{HNO}_{3}$ and $\mathrm{HCl}$ acid solution (1: 3). Samples were analyzed using atomic absorption spectrophotometer (AAS) and the absorbance values obtained was included into a calibration curve so that lead levels in the sample can be calculated. The results of the analysis showed that the largest lead levels were found in lipstick preparations, which amounted to $23.1683 \pm 0.1225 \mathrm{mg} / \mathrm{kg}$ and the lowest lead levels were found in loose powder preparations which were $0.6001 \pm 0.0092 \mathrm{mg} / \mathrm{kg}$. All eye-liner pencil, loose powder and lipstick
\end{abstract}


preparations marketed in Surakarta City have met the requirements for the maximum lead content required by BPOM, except for two lipstick samples which have not registered by BPOM.

Keywords: Lead; Eye-liner pencil; Compact Powder; Lipstick; Surakarta, Atomic absorption spectrophotometer

\section{Pendahuluan}

Dewasa ini, penggunaan sediaan kosmetik di Indonesia semakin meningkat. Penggunaan sediaan kosmetik bertujuan untuk mempercantik diri pengguna agar tampak lebih menarik dan menutupi kekurangan yang ada (Winanti, 2011). Beberapa sediaan kosmetika dekoratif yang sering digunakan oleh masyarakat adalah eye-liner pencil, bedak, dan lipstik. Sediaan kosmetik tersebut dipakai secara berulang setiap hari, sehingga diperlukan persyaratan yang aman untuk dipakai (Tranggono dan Latifah, 2007).

Sediaan kosmetik dapat dikatakan aman apabila memenuhi jumlah maksimum kadar timbal yang sesuai dengan persyaratan yang ada. Jumlah maksimum kadar timbal di beberapa negara ditetapkan sebesar 20 ppm dan tidak spesifik pada logam berat lainnya (Fernier, 2001). Hal itu juga dipertegas oleh Keputusan Kepala Badan POM tentang persyaratan cemaran mikroba dan logam berat dalam kosmetika, persyaratan cemaran logam berat timbal $(\mathrm{Pb})$ yakni tidak lebih dari $20 \mathrm{mg} / \mathrm{kg}$ (BPOM RI, 2014). Timbal dalam kosmetik merupakan cemaran (zat pengotor) pada bahan dasar pembuatan kosmetik. Bahan dasar pembuatan kosmetik seperti beewax secara alami mengandung $\mathrm{Pb}<10$ ppm, bahan pewarna seperti iron oxide mengandung kadmium <1 ppm dan timbal <10 ppm (Rowe, 2009). Selain itu, cemaran timbal dapat diperoleh pada saat proses produksi atau peralatan yang digunakan (Heep, dkk., 2009; Nourmoradi, dkk., 2013).

Timbal $(\mathrm{Pb})$ dapat masuk melalui penetrasi pada selaput atau kulit. Penyerapan lewat kulit dapat terjadi karena timbal dapat larut dalam minyak atau lemak. Gejala keracunan yang dihasilkan senyawa timbal $(\mathrm{Pb})$ tergolong dalam keracunan kronis dan akut yang menyebabkan kematian (Palar, 2008). Timbal dapat mempengaruhi sistem hematopoietic, sistem saraf, sistem urinaria, sistem gastro-intestinal,sistem kardiovaskuler, sistem reproduksi, sistem endokrin, dan bersifat karsinogenik dalam dosis yang tinggi (Widowati, dkk., 2008). Pada jaringan atau organ tubuh, timbal akan terakumulasi dan mempengaruhi hampir setiap organ dan sistem dalam tubuh. Paparan timbal jangka panjang dapat menyebabkan kerusakan beberapa organ tubuh. Gejala paparan timbal dapat berupa lemah, lesu, sakit perut, sembelit dan sakit kepala (Palar, 2008).

Berdasarkan hasil penelitian sebelumnya, terdapat beberapa kosmetik yang mengandung logam berat seperti bedak tabur produk dalam negeri dan produk luar negeri (Supriadi, 2008) mengandung logam timbal dan kromium. Penelitian lain yang telah dilakukan menunjukkan bahwa terdapat logam berat timbal pada lipstik yang melebihi ambang batas penggunaan yang 
ditetapkan (Effendi, dkk., 2014). Selain itu berdasarkan hasil investigasi dari Badan Pengawas Obat dan Makanan (BPOM) masih banyak ditemukan sediaan kosmetik yang tidak memenuhi persyaratan (BPOM RI, 2018).

Berdasarkan masalah tersebut maka perlu dilakukan penelitian mengenai kadar timbal $(\mathrm{Pb})$ dalam beberapa sediaan kosmetik untuk mengetahui kelayakan penggunaan sediaan kosmetik meliputi eye-liner pencil, bedak, dan lipstik terutama yang beredar di Kota Surakarta.

\section{Bahan dan Metode}

\subsection{Alat dan bahan}

Alat-alat yang digunakan meliputi spektrofotomeri Sserapan stom (SSA) (Shimadzu type AA-6650), pemanas listrik (National), neraca analitik (Sartorius), alat-alat gelas (Pyrex). Bahanbahan yang digunakan berupa sampel sediaan kosmetik (eye-liner pencil, bedak, dan lisptik) yang beredar di Kota Surakarta, larutan standar Pb 1000 ppm (Merck), 1HNO 3 (merck), aquadest, $\mathrm{HCl}$ (Merck), dan aquadest.

\subsection{Teknik sampling dan kriteria sampel}

Teknik sampling yang digunakan pada penelitian ini adalah purposive sampling. Sampel sediaan kosmetik yang digunakan yaitu eye-liner pencil, bedak, dan lipstik dengan 5 merk berbeda. Pemilihan sampel didasarkan pada beberapa kriteria, yaitu: sampel beredar di Kota Surakarta, eyeliner pencil berwarna hitam, bedak padat berwarna coklat, lipstik berbentuk stick berwarna merah, dan harga sampel di bawah 50.000 rupiah.

\subsection{Preparasi sampel}

Sebanyak 5 gram sampel ditimbang dan dimasukkan ke dalam erlenmeyer. Ditambahkan $\mathrm{HNO}_{3}$ pekat dan $\mathrm{HCl}$ pekat dengan perbandingan 1:3 sebanyak $5 \mathrm{~mL} \mathrm{HNO}_{3}$ dan $15 \mathrm{~mL} \mathrm{HCl}$. Kemudian dipanaskan pada suhu rendah yang terkontrol hingga volume sampel sebanyak $10 \mathrm{~mL}$ dan selanjutnya dilakukan penyaringan menggunakan kertas Whatmaan No.42.

\subsection{Penentuan kurva kalibrasi timbal}

Larutan standar $\mathrm{Pb} 1000$ mg/L dibuat menjadi $10 \mathrm{mg} / \mathrm{L}$, dengan cara mengencerkan $1 \mathrm{~mL}$ larutan standar timbal $(\mathrm{Pb}) 1000 \mathrm{mg} / \mathrm{L}$ ke dalam labu takar $100 \mathrm{~mL}$ kemudian ditambah air sampai tanda batas dan dikocok. Selanjutnya dibuat dalam berbagai konsentrasi yakni 0;0,25; 1; 2,5; dan $5 \mathrm{mg} / \mathrm{L}$, kemudian diukur analisis menggunakan SSA dan dicatat absorbansinya kemudian dihitung menggunakan regresi linier.

\subsection{Penentuan batas deteksi dan batas kuantitasi}


Penentuan batas deteksi (LOD) dan batas kuantitasi (LOQ) dilakukan dengan mengukur serapan 10 buah blanko kemudian ditentukan konsentrasi menggunakan persamaan kurva kalibrasi. LOD dihitung dari 3 kali standar deviasi dan LOQ 10 kali standar deviasi.

\subsection{Penentuan akurasi dan presisi metode analisis}

Uji Akurasi dan presisi dilakukan dengan cara menambahkan larutan hasil destruksi dengan larutan standar timbal $(\mathrm{Pb}) 4 \mathrm{mg} / \mathrm{L}$. Nilai akurasi diperoleh dengan menghitung nilai \% recovery yang membandingkan antara konsentrasi total sampel yang diperoleh dari pengukuran dengan konsentrasi sampel sebenarnya (Persamaan 1).

$$
\text { recovery }=\frac{C 2-C 1}{C 3} \times 100 \%
$$

Persamaan 1. Uji akurasi dan presisi kadar timbal $(\mathrm{Pb})$ dalam beberapa sediaan kosmetik; Konsentrasi sampel + standar (C2), Konsentrasi sampel (C1) dan Konsentrasi analit yang ditambahkan (C3).

Nilai presisi diketahui dengan menghitung konsentrasi total sampel yang diperoleh dari pengukuran kemudian dikurangi dengan konsentrasi sampel sebenarnya dan dibagi dengan konsentrasi analit yang ditambahkan menggunakan persamaan regresi linier dan dihitung nilai presisi menggunakan menghitung nilai CV (Persamaan 2).

$$
\% \mathrm{CV}=\frac{S D}{\text { Rata-rata }} \times 100 \%
$$

Persamaan 2. Nilai perhitungan Coefficient Variation (CV) kadar timbal ( $\mathrm{Pb})$ dalam beberapa sediaan kosmetik. Keterangan: Standar Deviasi (SD).

\subsection{Analisis kandungan timbal dalam sampel}

Analisis kandungan logam timbal $(\mathrm{Pb})$ dalam sampel dilakukan dengan menggunakan spektrofotometri serapan atom nyala dengan menggunakan lampu katoda timbal pada panjang gelombang 283,3 nm. Konsentrasi $\mathrm{Pb}$ yang terdapat dalam sampel (x) dihitung dengan mensubstitusi nilai absorbansi yang didapat (y) ke persamaan regresi linear yang diperoleh dari kurva kalibrasi, kemudian didapatkan nilai a, b dan $\mathrm{r}$ dan dibuat persamaan regresi liniernya yaitu $\mathrm{y}=\mathrm{bx}+\mathrm{a}$.

\section{Hasil dan Pembahasan}

\subsection{Kurva kalibrasi timbal}

Hasil pengukuran kurva kalibrasi timbal ditunjukkan Gambar 1. Berdasarkan data tersebut dapat dibuat hubungan antara absorbansi dengan konsentrasi sehingga diperoleh kurva kalibrasi standar timbal dengan persamaan garis $\mathrm{y}=0,0102 \mathrm{x}-0,000527$ dan nilai koefisien korelasi (r) yaitu sebesar 0,9997. Harga koefisien korelasi (r) yang mendekati 1 dari kurva kalibrasi menunjukkan 
korelasi antara konsentrasi dan absorbansi. Hal ini sesuai dengan hukum Lambert - Beer yaitu A = abc, dimana nilai absorbansi (A) berbanding lurus dengan nilai konsentrasi (c) (Day dan Underwood, 2002). Koefisien korelasi (r) yang diperoleh dari kurva kalibrasi larutan standar timbal dapat dikatakan memenuhi syarat kelinearan garis berdasarkan kriteria yang dikeluarkan oleh AOAC (2012), dimana r > 0,9950, sehingga dapat disimpulkan bahwa kurva kalibrasi yang didapatkan memiliki linieritas yang baik.

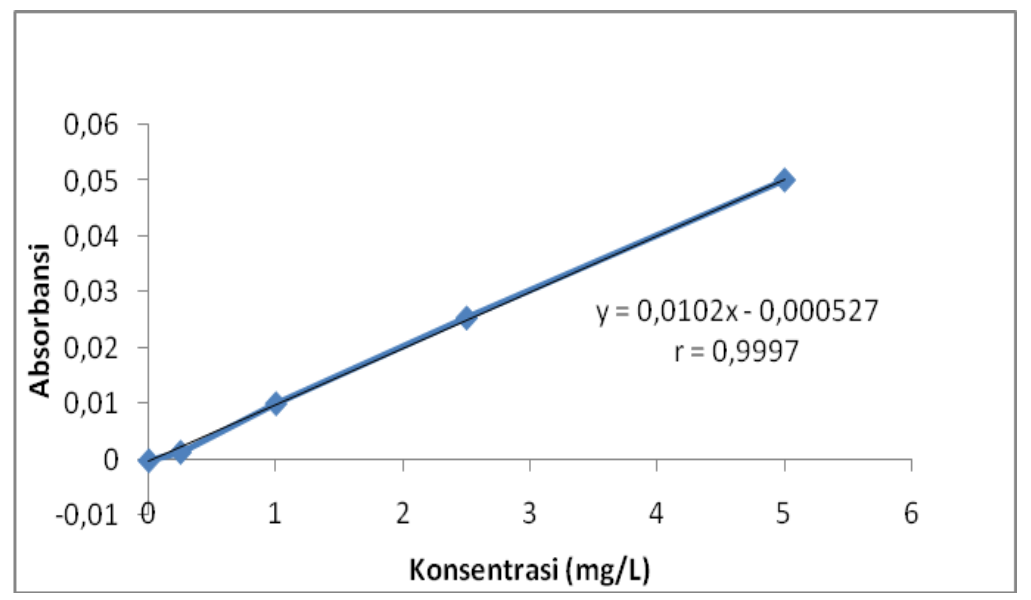

Gambar 1. Kurva standar kalibrasi timbal menggunakan spektrofotometri serapan atom nyala dengan menggunakan lampu katoda timbal pada panjang gelombang 283,3 nm.

\subsection{Batas deteksi dan batas kuantitasi timbal}

Batas deteksi (LOD) merupakan parameter uji batas analit minimal yang masih dapat dibedakan antara sampel dengan standar. Penentuan nilai LOD bertujuan mengevaluasi kemampuan metode dalam mengkuantitasi analit. Nilai LOD yang diperoleh yaitu sebesar 0,0861 mg/L. Batas kuantisasi (LOQ) adalah jumlah terkecil dari analit yang terkandung di dalam sampel yang masih dapat dikuantifikasi secara presisi dan akurasi (Harmita, 2004). Nilai LOQ yang didapatkan yaitu sebesar 0,2870 mg/L. Berdasarkan nilai LOD dan LOQ tersebut, maka konsentrasi analit yang berada di bawah $0,0861 \mathrm{mg} / \mathrm{L}$ tidak dapat dibedakan antara analit dengan blanko, sedangkan apabila konsentrasi analit berada di bawah 0,2870 mg/L memiliki tingkat kuantifikasi dari analit yang kurang akurat.

\subsection{Akurasi dan presisi}

Akurasi yang merupakan ukuran dimana menunjukkan derajat kedekatan hasil analisis dengan kadar analit sebenarnya yang dinyatakan sebagai \% recovery. Recovery merupakan perbandingan dari hasil yang diperoleh dan hasil sebenarnya. Hasil dari prosedur ini diperoleh dengan cara membandingkan hasil dari sampel dengan penambahan standar dan sampel tanpa penambahan standar. Larutan standar yang digunakan pada pengujian kali ini memiliki konsentrasi sebesar $4 \mathrm{mg} / \mathrm{L}$ dan ditambahkan sebanyak $5 \mathrm{~mL}$. Selanjutnya dilakukan analisis dan dihitung \% 
recovery. Pada pengujian ini syarat \% recovery adalah rentang 85-110\% (AOAC, 2012). Hasil rata-rata \% recovery yang diperoleh dari pengujian sampel eye-liner pencil, bedak, dan lipstik berturut-turut sebesar 98,17\%; 100,41\%; dan 97,06\%. Dengan demikian, metode analisis memenuhi persyaratan dan memiliki akurasi yang baik.

Presisi adalah ukuran kedekatan nilai data satu dengan yang lainnya dalam suatu pengukuran pada kondisi analisis yang sama. Berdasarkan hasil penentuan koefisien variasi yang diperoleh dari rata-rata sampel eye-liner pencil, bedak, dan lipstik berturut-turut adalah sebesar 1,11\%; 1,05\%; dan 0,21\%. Dari hasil teresebut, diperoleh bahwa semua sampel memiliki nilai koefisien variasi (RSD) kurang dari $5 \%$. Hal ini menginformasikan bahwa sistem operasional alat dan analisis memiliki presisi yang cukup baik terhadap metode dengan respon yang kurang konstan, sehingga hasil pengukuran untuk sampel telah memenuhi syarat yaitu kurang dari $5 \%$ (AOAC, 1993).

\subsection{Analisis kandungan timbal dalam sampel}

Sampel sediaan kosmetik dipreparasi menggunakan metode dekstruksi basah dengan penambahan asam pekat dan dipanaskan pada suhu yang rendah sebagai proses pemutusan ikatanikatan senyawa organik yang terdapat dalam sampel sehingga yang tersisa hanya senyawa anorganik. Proses destruksi dilakukan pada suhu $100^{\circ} \mathrm{C}$ dikarenakan asam nitrat memiliki titik didih $121^{\circ} \mathrm{C}$ agar dapat mencegah larutan asam nitrat cepat habis sebelum proses destruksi selesai (Wulandari dan Sukesi, 2013). Sampel selanjutnya dianalisis menggunakan SSA yang menganalisis secara spesifik senyawa yang dianalisis dengan prinsip absorbsi cahaya oleh atom yang terdapat di dalam sampel. Intensitas radiasi yang diserap oleh atom dalam sampel akan sebanding dengan jumlah atom dalam sampel, sehingga konsentrasi logam di dalam sampel dapat ditentukan.

Dari hasil analisis kandungan timbal dalam sediaan eye-liner pencil yang beredar di kota Surakarta terlihat bahwa semua sampel yang dianalisis memenuhi persyaratan. Hasil analisis kandungan timbal dalam sediaan bedak menunjukan bahwa kadar timbal juga memenuhi persyaratan. Hasil analisis pada sediaan lipstik terdapat 2 merek lipstik yang tidak memenuhi persyaratan yang telah ditetapkan berdasarkan persyaratan cemaran mikroba dan logam berat dalam kosmetika, dimana cemaran logam berat timbal $(\mathrm{Pb})$ tidak boleh lebih dari $20 \mathrm{mg} / \mathrm{kg}$ (BPOM RI, 2014). Sampel lipstik yang tidak memenuhi persyaratan tersebut merupakan sampel lipstik yang tidak teregistrasi BPOM. Hal ini dapat disebabkan karena tidak adanya pengawasan dari BPOM sehingga tidak dapat dipastikan apakah bahan baku dan proses pembuatan lipstik sudah sesuai dengan keputusan Kepala BPOM RI nomor HK.00.05.4.3879 tentang pedoman cara 
pembuatan kosmetik yang baik (BPOM RI, 2003). Hasil analisis kandungan timbal dalam sampel secara lengkap dapat dilihat pada Tabel 1.

Tabel 1. Hasil analisis kandungan timbal dalam beberapa sediaan kosmetik meliputi eye-liner pencil, bedak, dan lipstik terutama yang beredar di Kota Surakarta

\begin{tabular}{|c|c|c|c|}
\hline Jenis Sampel & Sampel & Kadar \pm SD $(\mathrm{mg} / \mathrm{kg})$ & Keterangan \\
\hline \multirow{5}{*}{ Eye-liner pencil } & 1 & $0,6263 \pm 0,0244$ & Memenuhi Syarat \\
\hline & 2 & $1,1165 \pm 0,0244$ & Memenuhi Syarat \\
\hline & 3 & $0,9726 \pm 0,0404$ & Memenuhi Syarat \\
\hline & 4 & $0,7373 \pm 0,0244$ & Memenuhi Syarat \\
\hline & 5 & $0,6981 \pm 0,0244$ & Memenuhi Syarat \\
\hline \multirow{5}{*}{ Bedak } & 1 & $0,7831 \pm 0,0092$ & Memenuhi Syarat \\
\hline & 2 & $1,5216 \pm 0,0185$ & Memenuhi Syarat \\
\hline & 3 & $0,6001 \pm 0,0092$ & Memenuhi Syarat \\
\hline & 4 & $2,5674 \pm 0,0244$ & Memenuhi Syarat \\
\hline & 5 & $0,7635 \pm 0,0092$ & Memenuhi Syarat \\
\hline \multirow{5}{*}{ Lipstik } & 1 & $9,3780 \pm 0,0800$ & Memenuhi Syarat \\
\hline & 2 & $0,7633 \pm 0,0249$ & Memenuhi Syarat \\
\hline & 3 & $0,8353 \pm 0,0185$ & Memenuhi Syarat \\
\hline & 4 & $22,4300 \pm 0,5470$ & Tidak Memenuhi Syarat \\
\hline & 5 & $23,1683 \pm 0,1225$ & Tidak Memenuhi Syarat \\
\hline
\end{tabular}

\section{Kesimpulan}

Sediaan kosmetik eye-liner pencil, bedak, dan lipstick yang beredar di Kota Surakarta telah memenuhi persyaratan batas maksimum kandungan timbal yang dipersyaratkan oleh BPOM, kecuali dua sampel lipstik yang tidak teregistrasi BPOM.

\section{Ucapan Terimakasih}

Penelitian ini dapat terlaksana atas dukungan dari Universitas Sebelas Maret.

\section{Daftar Pustaka}

AOAC. (1993). Peer Verified methods Program. Manual on Policies and Procedures. Arlington, VA.

AOAC. (2012). Official Methods Of Analysis, Appendix K: Chemical Methods for Dietary Supplements and Botanical, 19 edition. AOAC International, Gaithersburg.

BPOM RI. (2003). Keputusan Kepala Badan Pengawas Obat dan Makanan Republik Indonesia Nomor HK.00.05.4.1745 Tentang Kosmetik. Departemen Kesehatan Republik Indonesia, Jakarta.

BPOM RI. (2014). Peraturan Kepala Badan Pengawas Obat dan Makanan Republik Indonesia Nomor 17 Tahun 2014 tentang Perubahan atas Peraturan Peraturan Kepala Badan Pengawas Obat dan Makanan Nomor HK.03.1.23.07.11.6662 Tahun 2011 Tentang Persyaratan Cemaran Mikroba dan Logam Berat dalam Kosmetika. Departemen Kesehatan Republik Indonesia, Jakarta. 
BPOM RI. (2018). Public Warning No. B-HM.01.01.1.44.11.18.5410 tentang Kosmetika Mengandung Bahan Berbahaya. Badan Pengawasan Obat dan Makanan, Jakarta.

Day, R.A. dan Underwood, A.L. (2002). Analisis Kimia Kuantitatif, Edisi Keenam. Erlangga, Jakarta.

Effendi, N., Pratama, M. dan Kamaruddin, H. (2014). Analisis Kandungan Logam Berat Merkuri $(\mathrm{Hg})$ dan Timbal $(\mathrm{Pb})$ pada Kosmetik Lipstik yang Beredar di Kota Makassar dengan Metode Spektrofotometri Serapan Atom. As-Syifaa, 6(1), 82-90.

Fernier, D.J. (2001). Assessment of Some Heavy Metals in Facial Cosmetic Products. eMed. J. $2(5), 1-7$.

Harmita (2004). Petunjuk Pelaksanaan Validasi Metode dan Cara Perhitungannya. Majalah Ilmu Kefarmasian, 1(3), 117-135.

Heep, N.M., Mindak, W.R. dan Cheng, J. (2009). Determination of Total Lead in Lipstick: Development and Validation of a Microwave-assisted Digestion, Inductively Coupled Plasma-mass Spectrofometric Method. J. Cosmet. Sci., 60, 405-414.

Nourmoradi, H., Foroghi, M., Farhadkhani, M. and Vahid, D.M. (2013). Assessment of Lead Cadmium Levels in Frequently Used Cosmetic Products in Iran. Journal of Environmental and Public Health, 2013, 1-5.

Palar, H. (2008). Pencemaran dan Toksikologi Logam Berat. PT. Rineka Cipta, Jakarta.

Rowe, P.J. (2009). Handbook of Pharmaceutical Excipient. The Pharmaceutical Press, USA.

Supriyadi (2008). Analisis Logam Kadmium, Timbal, dan Krom pada Lipstik Secara Spektrofotometri Serapan Atom. Jurnal Kimia dan Teknologi, 4: 299-305.

Tranggono, R.I., Latifah, F., 2007. Buku Pegangan Ilmu Pengetahuan Kosmetik. Penerbit Pustaka Utama, Jakarta.

Widowati, W., Sastiono, A. dan Jusuf, R.R. (2008). Efek Toksik Logam Pencegah dan Penanggulangan Pencemaran. Penerbit Andi, Yogyakarta.

Winanti, M.B. (2011). Pengaruh Kompetensi Terhadap Kinerja Karyawan (Survei Pada PT Frisian Flag Indonesia Wilayah Jawa Barat). Jurnal Majalah Ilmiah Unikom, 7(2), 249-267.

Wulandari, E.A. dan Sukesi, (2013). Preparasi Penentuan Kadar Logam Pb, Cd dan Cu dalam Nugget Ayam Rumput Laut Merah (Eucheuma cottonii). Jurnal Sains dan Seni Pomits. 2(2), $15-17$. 